\title{
GESTIÓN CREDITICIA EN LA BANCA DE DESARROLLO Y EL PRESUPUESTO PÚBLICO PERUANO. PERÍODO: 2010-2014
}

\section{CREDIT MANAGEMENT IN THE DEVELOPMENT BANK AND THE PERUVIAN PUBLIC BUDGET. PERIOD: 2010-2014}

\author{
Cleofé Maritza Verástegui Corrales \\ Doctora en Política Fiscal y Sistema Tributario - Universidad Nacional Mayor de San Marcos, Lima, Perú. \\ Email: cverasteguic@unmsm.edu.pe (Autor Corresponsal) \\ Martha Karina Amezcua Luján \\ Doctora en Estudios Fiscales - Universidad de Guadalajara - México. \\ Email: karina.amezcua@cusur.udg.mx
}

[Recibido: 20/12/2016 Aceptado: 10/02/2017]

\section{RESUMEN}

El objetivo del estudio fue analizar la gestión crediticia en la banca de desarrollo y el presupuesto público peruano en el periodo 2010-2014 años tomando como base diversas cuentas contables, tales como colocaciones, provisiones, patrimonio. El estudio fue tanto cuantitativo como cualitativo y se enfoca específicamente en el Banco Agropecuario-Agrobanco por la participación del Estado con un 100\% y porque a través de este se ejecutan las políticas públicas. El análisis buscó establecer una relación directa entre la gestión crediticia en la banca de desarrollo y el Presupuesto Público Peruano. De los resultados obtenidos la correlación entre los gastos de provisiones para incobrabilidad en resultados con la cuenta patrimonial fue alta, lo cual conlleva a requerimiento de incremento del capital. En estudios posteriores se puede determinar la sostenibilidad operativa y financiera de la banca de desarrollo en el Perú.

\section{PALABRAS CLAVE}

Gestión crediticia, banca de desarrollo, presupuesto público, riesgo.

\begin{abstract}
The objective of the study was to analyze credit management in development banking and the Peruvian public budget in the period 2010-2014 years based on various accounting accounts, such as placements, provisions, equity. The study was both quantitative and qualitative and focuses specifically on the Agro-Agricultural Bank-Agrobanco due to the participation of the State in a $100 \%$ and because this is the implementation of public policies. The analysis sought to establish a direct relationship between credit management in development banks and the Peruvian Public Budget. From the results obtained, the correlation between the expenses of provisions for uncollectibility in results with the equity account was high, which entails a requirement to increase capital. In subsequent studies, it is possible to determine the operational and financial sustainability of development banks in Peru.
\end{abstract}

\section{KEYWORDS}

Credit management, development banking, public budget, risk. 


\section{INTRODUCCIÓN}

La liquidación de la Banca de Fomento en el Perú en julio del año 1992 es el resultado de una serie de errores en la gestión, supervisión, y la falta de sofisticación de instrumentos en el sector, entre otros. De acuerdo al Informe especial de investigación: proceso de liquidación de la banca de fomento emitido por el Congreso de la República, la decisión fue tomada porque se asumió que la banca privada supliría el vacío dejado por esta banca, sin embargo, ni la Banca Múltiple ni las Instituciones Microfinancieras lograron llegar a los segmentos de menores ingresos porque son distintos tipos de riesgos y requieren de un diseño y tecnología particular además de la asimetría en la información. Mediante Decreto Ley N ${ }^{\circ} 25478$ del 05.07.92, se declaró a los Bancos Estatales de Fomento Agrario, Industrial, Minero y de Vivienda del Perú, en estado de disolución para la liquidación definitiva de sus bienes y negocios, disponiendo asimismo que por Resolución Suprema del Ministerio de Economía y Finanzas se designara a las Comisiones Liquidadoras de los indicados bancos con las facultades previstas del Decreto Legislativo $\mathrm{N}^{\circ} 637$. Esta mala experiencia del Estado en esta Banca tuvo un costo neto de US\$.555 millones que incluyó deudas asumidas por el Ministerio de Economía y Finanzas.

Del análisis realizado podemos concluir que la gestión de esta banca no fue exitosa por la falta de conocimiento y experiencia de la gerencia de turno en el negocio bancario especializado además de que fue utilizado con otros fines y no con el fin para los cuales fueron creados.

El negocio bancario en un banco comercial y un banco de desarrollo se diferencia por el fondeo mientras que en un banco comercial es a tra- vés de las captaciones del público, en un banco de desarrollo tiene la forma de transferencias del Estado. Otra diferencia es la gestión crediticia, en un banco comercial la prudencia en el manejo de los recursos es una política, en un banco de desarrollo los recursos son de uso político. Existen otras diferencias, pero sólo se tomaran en cuenta las señaladas anteriormente porque se relacionan con la presente investigación.

La banca de desarrollo existe por razones políticas, económicas, culturales y sociales, pero sin una buena gestión no puede ser sostenible en el tiempo por lo que debe convertirse en una entidad eficiente ayudando al desarrollo de sus clientes y a la expansión de las finanzas rurales y de esa manera contribuir al crecimiento de nuestro país y no ser una carga que asumir en el futuro.

En América Latina, existen entidades financieras de desarrollo que atienden al agro y al medio rural, encontrándose muchas experiencias exitosas, y considerando que el sector agropecuario es muy importante en un país es que resulta relevante realizar este estudio.

El objetivo de la investigación es analizar la relación directa entre la gestión crediticia en la banca de desarrollo y el Presupuesto Público Peruano. Este trabajo de investigación busca aportar en la optimización en la gestión de los recursos públicos sin dejar de cumplir con el rol social de atender a los sectores de extrema pobreza, en los que se tiene como objetivo la reflexión académica.

Se tuvo que afrontar limitaciones como la obtención de información, datos celosamente guardados por los diversos estamentos, sin embargo, esto fue obviado por la colaboración de colegas trabajando en diversos niveles de la administración pública.

La disolución y liquidación de una institución conlleva un costo que todos los peruanos de ahora y futuros tenemos que pagar con el incremento de los impuestos a fin de cubrir los gastos del presupuesto público, esto porque no se realiza una eficaz gestión de los recursos públicos en la gestión de la banca de desarrollo y que además el Gobierno no cumple uno de sus roles: atender al mercado rural y contribuir a la reducción de los niveles de extrema pobreza.

Los motivos que impulsaron al graduando en el desarrollo del presente trabajo, es haber participado en la gestión de un banco de fomento el cual finalmente fue disuelto y liquidado en el año 2013, institución con más de 30 años al servicio de personas de bajos recursos económicos que requerían mejorar su calidad de vida, a través de la adquisición de un terreno y/o la construcción de su vivienda, porque previamente me desempeñé en un banco comercial de primer orden donde la gestión crediticia es sumamente importante, por el impacto en los resultados financieros, y considerando que los estados financieros son universales, es que analice la problemática en la banca de desarrollo peruana, confirmando que la gestión no consideró las teorías básicas y fundamentales del crédito y del presupuesto.

\section{Teoría del crédito}

Von (1936), expresa de manera precisa la actividad de los bancos como negociadores de crédito: "la fecha en que vencen las obligaciones del banco no deben preceder a la fecha en que las obligaciones frente a él puedan hacerse efectivas" (pp. 297-298). 
De otro lado, manifiesta que sólo así puede evitarse el riesgo de insolvencia y la certeza de que queda un riesgo; pero que la concesión imprudente de créditos puede ser de consecuencias tan ruinosas para un banco como para cualquier otro comerciante $y$ es precisamente la existencia de este riesgo lo que hace provechoso para el banquero el representar el papel de intermediario entre el que da un crédito y el que lo recibe. Y que de la aceptación de este riesgo es de donde el banco obtiene sus beneficios y sus pérdidas.

Von (1936) enmarca el negocio bancario en la toma de riesgos, esto es, el banco tiene como objetivo principal el control de los riesgos financieros que enfrenta, siendo el riesgo de crédito el de mayor importancia porque depende de este su nivel de pérdidas.

Freixas y Rochet (1999), mencionan que cuando aparecieron los primeros préstamos bancarios en Florencia, Siena y Lucca y, más tarde, en Venecia y Génova, éstos iban destinados únicamente a la financiación de las cosechas y que era posible observar y valorar. Sin embargo, la financiación de las guerras pronto se convirtió en una importante actividad bancaria. Aun así, los banqueros trataban de que sus préstamos fueran seguros, bien por medio de garantías (joyas), de la asignación de derechos (impuesto sobre consumos específicos) o generalmente a través de un ayuntamiento (que, a diferencia de los reyes, podía ser demandado en caso de impago). También, señalan que con el paso del tiempo el riesgo de estos préstamos ha aumentado y que cuando los préstamos realizados por un banco son arriesgados, los contratos necesarios son mucho más complejos, ya que entran en juego algunas cuestiones relacionadas con la aversión al riesgo y con el riesgo moral.
Stiglitz (2013), señala que:

La política monetaria funciona aumentando la disponibilidad de dinero y crédito y facilitando los términos de los préstamos. La disponibilidad de crédito se produce básicamente a través de los sistemas bancario y financiero. Manifiesta que el proporcionar más liquidez a las instituciones financieras no significa necesariamente que se concedan más créditos y en las circunstancias a que se enfrenta hoy el mundo puede darse una trampa en la cuestión de liquidez. De otro lado, señala que los bancos que han visto erosionarse sus ingresos y que se enfrentan a la perspectiva de altos índices de impagos sobre préstamos arriesgados ya concedidos no están dispuestos a aumentar el crédito y que puede suceder que se trate de una reacción excesiva: un episodio de riesgo excesivo puede ser seguido de un episodio de precaución excesiva. De ser este el caso, los gobiernos deben asumir un papel más activo a la hora de absorber parte del riesgo de prestar crédito (p. 85).

\section{Teoría del presupuesto}

García (1998), señala que en la doctrina financiera se manejan dos tesis fundamentales con respecto a la ley de presupuesto, que ya hemos adelantado. ¿Es una ley formal o es una ley material?

La tesis que sostiene que la ley de presupuesto es una ley formal, tiene origen en las disputas políticas entre el Parlamento alemán y el canciller Bismarck en la segunda mitad del siglo XIX. A partir de este problema político Paul Laband, plasmó en un libro, una construcción jurídica muy coherente para sostener la posición del Canciller. A continuación, juristas alemanes se plegaron a esta tesis, que con el tiempo pasó a Francia y de ahí al resto de Europa y América.

Junto con los que sostienen que la ley de presupuesto es una ley formal, surgieron algunos que defendieron lo contrario, es decir, que es una ley material. Ambas posiciones con algunos matices, con una infaltable posición ecléctica, son las más importantes y las que pasaremos a detallar. En esencia son posiciones extremas y antagónicas, pero interesantes e ineludibles. Consideramos que en la actualidad, la doctrina moderna se ha inclinado por no hacer esta distinción, entre otras cosas, por encontrarse en cuestionamiento clasificar las leyes de esta manera y por su inutilidad para explicar la naturaleza jurídica del presupuesto (p. 17).

Shack (2006), define al Presupuesto Público como el principal instrumento de programación del Estado para el cumplimiento de sus funciones, misión y objetivos nacionales, a la vez que instrumento para la política económica. Por tal razón, las funciones de asignación, distribución y estabilización, inherentes al Estado en su conjunto, son (o deberían ser) instrumentalizadas a través del presupuesto. Por otro lado señala que si bien la normatividad del proceso presupuestario contiene los objetivos inherentes a un proceso óptimo de presupuestación, no se ha avanzado lo suficiente para que los pliegos conozcan qué es lo que lograrán con las asignaciones de recursos y cómo ejecutan con mayor eficiencia y eficacia, es decir, se dice qué es lo que se desea pero no se dice cómo se logrará (p. 10).

\section{MATERIAL Y MÉTODOS}

La investigación a realizar es de tipo correlacional porque se tiene como propósito mostrar la relación entre 
las variables de gestión del crédito y el presupuesto público peruano.

Para el desarrollo de la investigación en el enfoque cuantitativo, en base a la revisión teórica se ha aplicado la herramienta estadística coeficiente de correlación de Pearson (r).

La unidad de análisis es la institución bancaria Agrobanco; se ha trabajado únicamente con Agrobanco porque es el único banco de desarrollo $100 \%$ del Estado que sobrevive, sin embargo, la documentación presentada permite entrever similitud con otras entidades financieras de desarrollo.

La base de datos utilizada para el análisis empírico consiste en partidas (cuentas) contables y series de tiempo en frecuencia anual entre el $2010 \mathrm{y}$ 2014. Las cuentas contables que componen la base de datos son:

- Créditos Directos

- Créditos Atrasados: vencidos y en cobranza judicial

- Provisiones de Créditos

- Provisiones por Incobrabilidad de Créditos

- Patrimonio

- Margen Financiero Neto

- Cartera de Alto Riesgo (CAR)

\section{RESULTADOS}

Descripción de la banca de desarrollo peruana en el sector rural

Al mes de diciembre de 2008, la banca de desarrollo peruana en el sector rural estaba conformada por tres entidades públicas: Banco de la Nación, Banco Agropecuario y COFIDE, pero con diferencias como la participación del Estado y la modalidad operativa; en las dos primeras, la participación del Estado es del 100\% con modalidad operativa de primer y segundo piso. Las operaciones que realiza la banca de desarrollo están normadas por la SBS, de acuerdo con la Ley General del Sistema Financiero y Orgánica de la SBS N²6702 (en adelante Ley General) y sus modificatorias.

La Ley General establece el marco de regulación y supervisión a que se someten las empresas que operen en el sistema financiero y de seguros, así como aquéllas que realizan actividades vinculadas o complementarias al objeto social de dichas personas.

Análisis del Banco Agropecuario S.A. Durante el "Oncenio" se inauguró la banca de fomento, teniendo como rol principal ser el promotor del desarrollo económico. En 1928, inició sus funciones el Banco de Crédito Agrícola, que debía impulsar la producción agropecuaria en el país. Pero, lamentablemente los créditos fueron destinados a los barones del azúcar y del algodón, más no a los pequeños propietarios o a las comunidades campesinas de la sierra.

En el periodo 1930-1950 una de las características de la política bancaria fue la formación de la banca de fomento, como Banco Agrícola en 1931, Banco Industrial del Perú en 1936 y Banco Minero del Perú en 1942. Luego se integró a esta banca el Banco de la Vivienda en 1962.

Cortez (2001) indica que en 1963 se amplió la participación privada en la banca de fomento, se creó la banca privada de fomento y en 1967 el Sistema Nacional de Banca y Crédito Agropecuario y se autorizó el establecimiento de los Bancos Privados de Fomento Agropecuario, los Bancos Cooperativos de Fomento Agropecuario y las Cajas Rurales de Crédito. (p. 97)

Luego, mediante Decreto Ley $\mathrm{N}^{\circ}$
25478 del 05.07.92, declara a los Bancos Estatales de Fomento Agrario, Industrial, Minero y de Vivienda del Perú, en estado de disolución para la liquidación definitiva de sus bienes y negocios.

Posteriormente, en el año 2001 se emite la Ley de Creación del Banco Agropecuario Ley $\mathrm{N}^{\circ} 27603$ (en adelante, Agrobanco). En esta ley se indica que la creación del banco fue por necesidad pública y por conveniencia nacional para integrar el sistema financiero nacional, teniendo como finalidad otorgar créditos al sector agropecuario, el cual comprende el agro, la ganadería, la acuicultura y actividades de transformación y comercialización de los productos del servicio agropecuario y acuícola según el Artículo 60 de la Constitución Política del Estado. El apoyo financiero y técnico a la pequeña agricultura y ganadería cuenta con los recursos que le asigne el Tesoro Público y las transferencias financieras que con cargo a su presupuesto debe realizar el de Agricultura y otros Pliegos presupuestarios que desarrollan programas de apoyo financiero al sector agropecuario y acuícola; estas transferencias formarán parte del patrimonio del Banco Agropecuario. Nació como persona jurídica de derecho privado, de capital mixto, sujeto al régimen de la Ley $N^{\circ} 26702$ - Ley del Sistema Financiero y del Sistema de Seguros y AFP (SBS), la Ley General de Sociedades, la Ley de su creación y las disposiciones vigentes de la misma.

Dentro de su estructura orgánica, existen dos áreas que han cumplido un papel importante en los últimos años, el área de riesgos y el área de negocios.

En la memoria de Agrobanco (2014), respecto a la gestión de riesgos es importante resaltar que: 
Sobre la base estratégica iniciada en el 2012 y 2013, de fomentar la cultura de gestión de riesgos en todos los procesos del banco, en el 2014 se continuó con la inserción de este conocimiento en los procesos críticos y de soporte. Se automatizaron los procesos $\mathrm{de}$ aprobación y se mantuvieron los estándares en la evaluación de los créditos. Se fortaleció el seguimiento de créditos a través de los oficiales de Riesgo en cada uno de los 52 puntos de atención (visitas pre y posdesembolso). Se establecieron los parámetros específicos para la admisión y evaluación de los créditos no minoristas a través de los mitigadores de riesgo. Por ejemplo, financiar proyectos con márgenes de maniobra mayores a dos veces el importe del crédito o relación garantía-deuda para créditos de mediano y largo plazos de 1.5 a 1 en base a garantías preferidas. Adicionalmente, calificar el carácter de los inversionistas, así como el impacto social y ambiental de los proyectos. Se implementaron cambios y precisiones a las políticas de prórrogas, reprogramaciones y refinanciaciones. Además de la estandarización de la ruta de aprobación crediticia, se recogieron las recomendaciones de la SBS (p. 68-69).

A diciembre de 2014, Agrobanco alcanzó un volumen de cartera de créditos de S/.1 338 millones, lo que representa un crecimiento de $57,4 \%$ con relación al mismo periodo del año anterior, con un ratio de cartera atrasada igual a 2,14\%, lo que su exposición es mayor con relación a diciembre 2013 $(1,64 \%)$. Asimismo, el ratio de cartera de alto riesgo, para el mismo periodo, aumentó de 3,45\% a 3,96\%, lo cual indicaba una deficiente administración de riesgos.

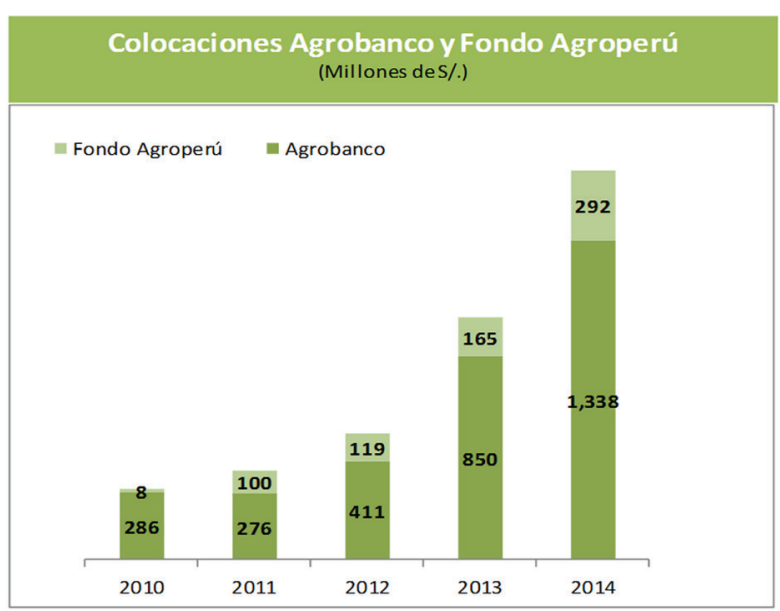

Figura 1. Colocaciones Agrobanco y Fondo Agroperú Fuente: Agrobanco 2015

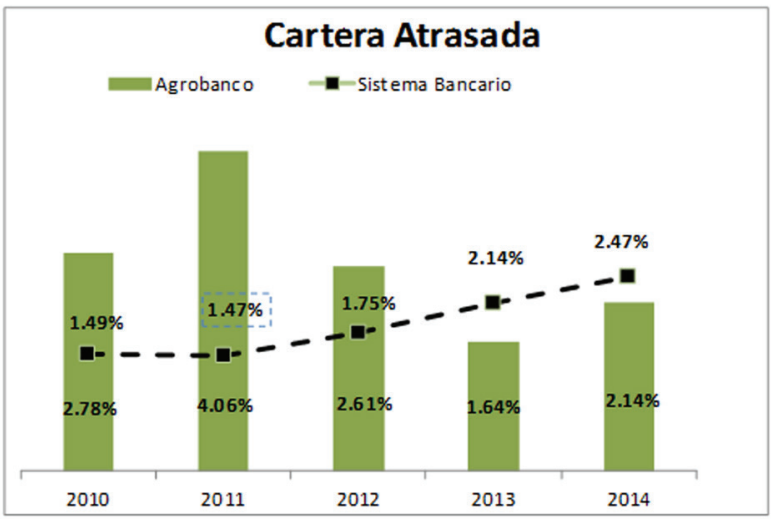

Figura 2. Cartera Atrasada

Fuente: Agrobanco 2015

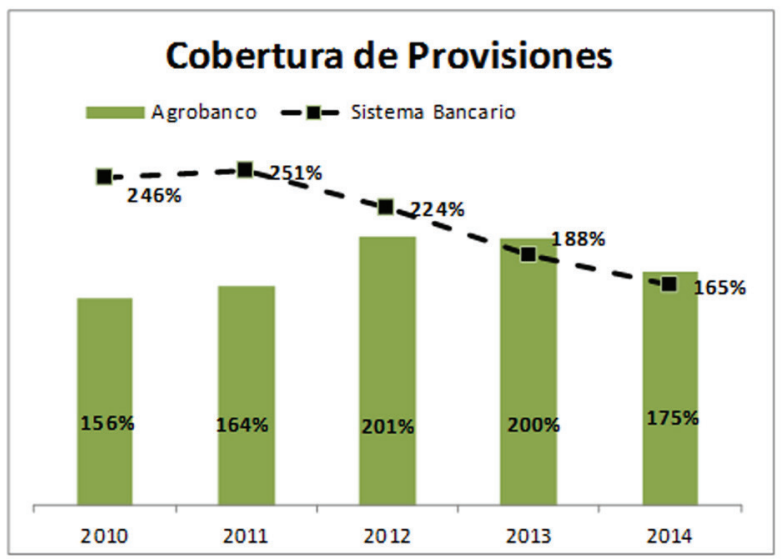

Figura 2. Cobertura de provisiones Fuente: Agrobanco 2015 


\section{DISCUSIÓN}

De los resultados del estudio se estableció la relación entre la gestión del crédito en la banca de desarrollo y el Presupuesto Público Peruano, esto es, si la cartera de créditos aumenta el Presupuesto Público Peruano también tiene que aumentar, para seguir atendiendo las necesidades de financiamiento del sector agropecuario.

Se ha determinado que una deficiente gestión del crédito en la banca de desarrollo reduce el patrimonio empresarial afectando el Presupuesto Público Peruano por lo que es importante mantener una cartera de créditos sana para evitar las provisiones por incobrabilidad.

Se ha establecido que la gestión del crédito en la banca de desarrollo, requiere mayor Cobertura de Cartera por la falta de medidas coercitivas para la recuperación del crédito, por lo que Agrobanco debe establecer una metodología para monitorear el comportamiento de la cartera de créditos a través de indicadores refinados de riesgo para la toma de medidas correctivas a tiempo.

En el 2017 Agrobanco recibirá una inyección de S/.500 millones de soles del Estado para mantener el di- namismo de la cartera de créditos y potenciar el crédito agrícola pero sino ha superado los controles y no ha afinado la gestión del crédito, el Estado tendría que inyectarle capital distrayendo esos recursos que bien podrían ser destinados a sectores más productivos y de bajo riesgo.

Existen experiencias de reformas exitosas en la banca de desarrollo que atienden al agro por lo que el Estado Peruano debería establecer un modelo de entidad financiera de desarrollo eficiente con una estrategia de reforma adecuada teniendo como objetivo a largo plazo el ser independiente de los recursos de los presupuestos públicos.

\section{REFERENCIAS BIBLIOGRÁFICAS}

Agrobanco (2014), Memoria anual. Recuperado de http://www.agrobanco.com.pe/data/uploads/memorias/ MEMORIA_2014_FINAL.pdf

Calderón, R. (2005). La banca de desarrollo en América Latina y el Caribe. Santiago: CEPAL.

Congreso de la República (2002). Informe especial de investigación: Proceso de liquidación de la banca de fomento. Recuperado de http://www.congreso. gob.pe/
Freixas, X., \& Rochet, J. (1997). Economía Bancaria. Madrid: Banco Bilbao Vizcaya.

García, D. (1998). El Derecho Presupuestario en el Perú. Lima: Luis Alfredo Ediciones SRL.

Gómez,P.\& Partal, A. (2010). Gestión $y$ control del riesgo de crédito en la banca. Madrid: Delta Publicaciones Universitarias.

Rahnema, A. (2007). Finanzas Internacionales. Barcelona: Ediciones Deusto.

Shack, N. (2006). Presupuestar en el Perú. Santiago de Chile: Naciones Unidas.

Stigliz, J. (2013). El Informe Stiglitz. (2da ed.). Barcelona: Antoni Bosch.

Von, L. (1936). Teoría del crédito y del dinero. (3ra. ed.). Madrid: UNIÓN EDITORIAL S.A.

Cortez, G. (2001). El desarrollo del sector rural: ¿Es un problema de financiamiento?. Revista de la Facultad de Ciencias Económicas de la Universidad Nacional Mayor de San Marcos, 6(20), 91-101. 